\title{
Role of Intra-Aortic Balloon Pump in Off-Pump Coronary Artery Bypass -A Vettath Modification
}

\author{
Murali P. Vettath ${ }^{*}$, Kannan A. Vellachamy ${ }^{2}$, Nitin Gangadharan ${ }^{2}$, \\ Sanooj Ottuparakuzhiyil'2, Jayaprakash Moothencherie ${ }^{3}$ \\ ${ }^{1}$ Department of Cardiac Surgery, Malabar Institute of Medical Sciences, Kozhikode, Kerala, India \\ ${ }^{2}$ Department of Cardiac Anaesthesia, Malabar Institute of Medical Sciences, Kozhikode, Kerala, India \\ ${ }^{3}$ Department of Perfusion Technology, Malabar Institute of Medical Sciences, Kozhikode, Kerala, India \\ Email: "mvettathcts@hotmail.com, "murali.vettath@gmail.com
}

Received 26 May 2016; accepted 26 June 2016; published 29 June 2016

Copyright (C) 2016 by authors and Scientific Research Publishing Inc.

This work is licensed under the Creative Commons Attribution International License (CC BY).

http://creativecommons.org/licenses/by/4.0/

(c) $\underset{\mathrm{EY}}{0}$ 0pen Access

\begin{abstract}
Objective: Hemodynamic deterioration during positioning of the heart has been the most critical complication of off-pump coronary artery bypass surgery. Pre-operative use of intra-aortic balloon pump has been shown to prevent this complication in high risk patients. The role of balloon pump in high risk patients has been questioned by our group. We modified the role of balloon pump in our patients, thus avoiding the conversion to cardiopulmonary bypass. Methods: 4063 off-pump coronary bypass surgeries were performed by a single surgeon in our center, over thirteen years. 130 intra-aortic balloons used between July 2002 and December 2015 were removed from the theater, once the distal anastomosis was performed. We studied this group of patients for-time and need for insertion, duration of balloon used, local insertion problems and survival. Results: Initially, we inserted intra-aortic balloons in high risk patients. We observed that, patients with low ejection fraction and patients with critical left main coronary artery disease were not the ones who actually needed balloon pump support. It was the patients who had ongoing ischemia, with preserved left ventricular function, and ST depression intra-operatively, who needed balloon pump support to perform complete anatomical revascularization. Conclusions: Intra-aortic balloon pump has helped us to position the heart without hemodynamic instability, thereby avoiding conversion to cardiopulmonary bypass. This enabled us to perform off-pump surgery in virtually all areas of the heart, thus maintaining perfect hemodynamics.
\end{abstract}

\section{Keywords}

Off-Pump Coronary Artery Bypass (OPCAB) Surgery, Intra-Aortic Balloon Pump (IABP)

\footnotetext{
${ }^{*}$ Corresponding author.
}

How to cite this paper: Vettath, M.P., Vellachamy, K.A., Gangadharan, N., Ottuparakuzhiyil, S. and Moothencherie, J. (2016) Role of Intra-Aortic Balloon Pump in Off-Pump Coronary Artery Bypass-A Vettath Modification. World Journal of Cardiovascular Diseases, 6, 188-195. http://dx.doi.org/10.4236/wjcd.2016.66020 


\section{Introduction}

The increase in OPCAB numbers has been aided by technical advances and increased surgical experience but had been limited by the lack of an effective technique for successful grafting of the posterior coronary branches of the left circumflex artery. Use of IABP has been shown to avoid complications in high risk patients, when used preoperatively [1]. To facilitate exposure of these vessels, and to overcome hemodynamic derangement during displacement of the heart, specialized surgical techniques and anesthetic support, such as placement of deep pericardial sutures, patient positioning, pharmacologic manipulation, widely opening the right pleura and sometimes, application of a suction-based cardiac positioning device, have been suggested [2]-[6]. The use of IABP, either preoperative or intraoperative to reduce operative risk and to facilitate posterior vessel grafting, has been well documented [7]. Preoperative IABP counter pulsation has been shown to have better outcomes compared with perioperative or postoperative insertion in critical patients [7]. Also, off-pump surgical procedures have been advocated to reduce mortality in such high-risk patients. In patients with high risk factors, higher mortality and morbidity rates have been demonstrated in spite of massive pharmacologic support combined with postoperative IABP support [7].

IABP therapy results in a more favorable myocardial blood supply, increased stroke volume and cardiac output through augmentation of the diastolic pressure, and after load reduction. Yet intra-operative and postoperative IABP insertion has been disappointing given the associated high mortality rate, as well as the high devicerelated complication rate [7].

IABP has been indicated in high-risk patients with left main coronary artery disease, intractable resting angina, post infarction angina, left ventricular dysfunction (ejection fraction $<35 \%$ ), or unstable angina [1]. We previously inserted the IAB in our patients who had any one of these high risk factors. However, we have recently resorted to introduce the IABP only in patients who became hemodynamically unstable during surgery. This was possible, as all our patients had a femoral arterial line in situ during induction. The IABP was then used to stabilize the patient during the distal anastomosis alone. After that it was kept on standby mode for the top end anastomosis, and then removed after heparin reversal.

\section{Materials and Methods}

Between July 2002 and Dec 2015, 4063 patients underwent OPCAB (Dr MPV) (Table 1) from our center. Every patient undergoing OPCAB had a femoral arterial line introduced after induction. This was used to monitor arterial pressure as well. We used IABP (Datascope Sensation 7.5 \& 8F, 30 \& 40 ml balloons; from Datascope Corp, Fairfield, NJ, USA and recently Arrow 7 - 8 F, 30 - 40 ml; Arrow International, Reading, PA, USA) sheathless insertion in all patients. In our earlier experience, when inotropes were being used, IAB was inserted in the OT and surgery was performed and patients were shifted to the ICU with the IAB in place. Eleven patients underwent this routine. They were then removed after 24 - $48 \mathrm{hrs}$. Those were the days when our conversion rate to $\mathrm{CPB}$ was high.

Since 2008 all the patients who had IAB inserted in the theater, had OPCAB performed, and their IAB removed in the OT (Table 1). We were initially inclined to introduce IAB in all the patients who fitted into the criteria of being high risk patients. In these patients, after the heparin was given, sheath less IAB was introduced. This was not inflated unless the patient developed hemodynamic compromise, while lifting the heart for grafting of the posterior or lateral wall coronaries. What we noticed was that after grafting the LAD (left anterior descending) artery, most of the patients with critical left main disease and low EF stabilized. Hence it was not necessary to inflate the balloon in the majority of patients (Table 2). This table shows that, of the 195 patients who had the IAB inserted, 54 of them did not have the IAB inflated, as they remained hemodynamically stable during the grafting. In fact, these patients had the IAB inserted as they were included in the high risk group as discussed above. As these IAB were not used, they were also removed after the grafting was completed and the heparin reversed. Table 2 shows that till 2006, 10 patients were shifted to the surgical ICU with the IAB in place. Subsequently, till 2015 we have had only one patient shifted to the surgical ICU with the IAB in place. After 2008, all the patients who had the IAB inserted, has had it removed in OT itself.

In our series, only patients with ongoing ST depression, recent myocardial infarction, tight circumflex stenosis and moderate ischemic mitral regurgitation, developed hemodynamic deterioration had the IAB inflated, and the distal coronary anastomosis performed. Once the heart was placed back in its position, the hemodynamics becomes stable. Then the proximal anastomosis is performed with the IABP on standby mode. Early in our 
Table 1. Total No. of off-pump.

\begin{tabular}{|c|c|c|c|c|c|}
\hline From & To & OPCAB & Conversion & IABP removed in OT & Mortality No \\
\hline 01-2003 & $12-2003$ & 177 & 12 & 0 & 0 \\
\hline 01-2004 & $12-2004$ & 238 & 6 & 0 & 1 \\
\hline 01-2005 & $12-2005$ & 299 & 0 & 0 & 3 \\
\hline 01-2006 & $12-2006$ & 284 & 0 & 4 & 5 \\
\hline 01-2007 & $12-2007$ & 260 & 1 & 8 & 0 \\
\hline 01-2008 & $12-2008$ & 224 & 0 & 11 & 2 \\
\hline 01-2009 & $12-2009$ & 280 & 0 & 8 & 0 \\
\hline 01-2010 & $12-2010$ & 358 & 0 & 22 & 0 \\
\hline 01-2011 & $12-2011$ & 413 & 0 & 24 & 0 \\
\hline 01-2012 & $12-2012$ & 425 & 0 & 23 & 2 \\
\hline 01-2013 & $12-2013$ & 429 & 0 & 18 & 2 \\
\hline 01-2014 & $12-2014$ & 312 & 0 & 6 & 3 \\
\hline 01-2015 & $12-2015$ & 317 & 0 & 6 & 2 \\
\hline Total & & 4063 & 19 (0.46\%) & 130 (3.19\%) & 20 (0.49\%) \\
\hline
\end{tabular}

Table 2. Statistics of IABP used.

\begin{tabular}{|c|c|c|c|c|c|c|}
\hline & Total OPCAB & IABP inflated & $\begin{array}{l}\text { Inflated removed } \\
\text { from OT }\end{array}$ & $\begin{array}{l}\text { Shifted with } \\
\text { IABP }\end{array}$ & $\begin{array}{l}\text { Not inflated } \\
\text { removed from OT }\end{array}$ & Total IABP used \\
\hline 07-2002 & 47 & 0 & 0 & 0 & 0 & 0 \\
\hline 01-2003 & 177 & 1 & 0 & 1 & 0 & 1 \\
\hline 01-2004 & 238 & 0 & 0 & 0 & 0 & 0 \\
\hline 01-2005 & 299 & 6 & 0 & 6 & 0 & 6 \\
\hline 01-2006 & 248 & 7 & 4 & 3 & 3 & 10 \\
\hline 01-2007 & 260 & 8 & 8 & 0 & 5 & 13 \\
\hline 01-2008 & 224 & 12 & 11 & 1 & 12 & 24 \\
\hline 01-2009 & 280 & 8 & 8 & 0 & 5 & 13 \\
\hline 01-2010 & 358 & 22 & 22 & 0 & 14 & 36 \\
\hline 01-2011 & 413 & 24 & 24 & 0 & 9 & 33 \\
\hline 01-2012 & 425 & 23 & 23 & 0 & 2 & 25 \\
\hline 01-2013 & 429 & 18 & 18 & 0 & 2 & 20 \\
\hline 01-2014 & 312 & 6 & 6 & 0 & 2 & 8 \\
\hline 01-2015 & 317 & 6 & 6 & 0 & 0 & 6 \\
\hline Total & 4063 & 141 & 130 & 11 & 54 & 195 \\
\hline
\end{tabular}


series, we were inclined to restart the IABP after the proximal anastomosis. But we noticed that all these patients in fact stabilized after the proximal anastomosis was completed. We then introduced another femoral arterial line in the other groin and then removed the IAB, after five minutes of reversing the heparin. This is now our routine. The femoral arterial line was then introduced to the other groin, so as to gain emergency access to femoral artery in case the patient needed it in the surgical ICU.

We used Chi square test only for the association of categorical variables. $\mathrm{P}$ value $<$ than 0.05 was considered statistically significant.

\section{Results}

We have audited all the patients who had the IABP used between July 2002-Dec 2015. In our 4063 OPCAB patients, we have used and removed IAB from OT in 130 patients. Though it was inserted in 195 patients, it was not inflated in 54 patients (Table 2). We used IABP in all these patients before starting any inotropes, and that prevented our conversion to CPB. Except in the initial stages of our work, we were able to remove all the IAB's inserted in our patients since 2008, in the OT itself. We were able to remove the IAB in all these patients and shift them to the ICU, without inotropes and without IAB (Table 2). Thus far we have not had to re-introduce the IAB in any of these patients.

The duration of the IABP in these patients in the OT are outlined in (Table 3(a)). We noticed that the use of IABP was primarily in patients with triple vessel disease (3.5\%) and that too in patients with tight circumflex lesion. Though we had inserted IAB in most of the patients with critical left main stenosis, we noticed that, out of the 504 left main patients that were operated on, only 14 (2.7\%) patients actually needed IABP to perform their distal anastomosis. Though we had inserted IABP in 46 left main patients with critical stenosis, only 14 were used. This reinforced our belief that it is not the anatomic position of the lesion, but the hemodynamic change that forced us to use the IABP (Table 3(b)). That is, only 2.7\% of LMCA patients actually needed IABP to perform OPCAB.

Another fact was that, though we had inserted IAB in mostly all patients with low EF (less than 35\%), in the initial stages, we had to inflate them only in very few patients. In patients with low EF, only $2.6 \%$ of patients had the IAB used and in patients with normal EF, we had 3.4\% of patients getting an IAB inserted. That was to infer that, it was not the ventricular function that decided on the use of IAB, but the ischemia that pushed us to use the IAB (Table 3(c)).

We have published our results of OPCAB regarding how we were able to avoid conversions to CPB after we had started liberally using the IABP (Table 1). It was noticed that in the first three years of our experience, our conversion on to CPB was high. But later on with the liberal use of IABP, our conversion to CPB decreased. Since 2005, we have had only one conversion to CPB till Dec 2015.

We audited our 4063 OPCAB patients by dividing them into two groups. First group was patients operated upto Dec 2006 (1045 patients) and the second group were patients since January 2007 till Dec 2015-3018 patients (Table 4). We noticed that our learning curve of OPCAB extended beyond the first 500 patients, where we had not yet standardized our techniques. We were still using inotropes for the first 1045 patients, but once we started using injection Atropine to increase the heart rate, then we noticed that it was easy to stabilize the heart during positioning, or by using the deep pericardial stitch. Earlier, we were using the IABP only after the inotropes were used, which made the patient more ischemic, and the need to continue the IABP postoperatively into the ICU. But when the IABP was used as the first resort to avoid conversion to the pump and the inotropes were not used, we found that patients stabilized very well. We were able to avoid conversions to CPB and also were able to remove the IAB in OT itself. With this modification, we have been able to perform OPCAB in nearly hundred percent of patients who come to our center to undergo CABG. We have been able to decrease our perioperative mortality rate, rate of myocardial infarction, rate of renal dysfunction etc., as shown in the Table 4, which shows a significant $\mathrm{P}$ value in all the parameters audited, except in Stroke rate and the mortality rate.

In patients with peripheral vascular disease, we have performed antegrade insertion of IAB in two patients, and were able to perform complete arterial revascularization without clamping the aorta. With the technique of sheath less insertion of IABP we were able to avoid the peripheral vascular complication of the use of IABP.

One patient developed loss of pulsation in his dorsalis pedis artery after removal of IAB in the OT itself. His femoral artery was explored and an embolectomy was done and a vein patch was used to close the arteriotomy site. 
Table 3. Statistics of IABP inserted and removed from OT from June 2002 to Dec 2015.

(a)

\begin{tabular}{ccccccc}
\hline Total No 184 & $10-15$ Min & $16-30$ Min & $31-45$ Min & $46-60$ Min & $>60$ Min & Total \\
\hline IABP inflated and removed from OT & 12 & 54 & 46 & 12 & 6 & 130 \\
IABP not inflated \& removed from OT & 54 & & & & & \\
\hline
\end{tabular}

(b)

\begin{tabular}{cccc}
\hline & \multicolumn{3}{c}{ Role of IABP in OPCAB } \\
\hline SVD & 0 & 0 & 130 \\
DVD & 5 & $11(1.8 \%)$ & 130 \\
TVD & 49 & $119(3.5 \%)$ & 3358 \\
LMCA $>$ 75\% & 46 & $14(2.7 \%)$ & 504 \\
Total & 54 & 130 & 4063 \\
\hline
\end{tabular}

(c)

\begin{tabular}{cccc}
\hline & \multicolumn{2}{c}{ Role of IABP in low EF } \\
\hline EF & IABP not inflated & IABP inflated & Total OPCABS \\
\hline$<35$ & 36 & $29(2.6 \%)$ & 1103 \\
$>35$ & 18 & $101(3.4 \%)$ & 2960 \\
Total & 54 & $130(3.19 \%)$ & 4063 \\
\hline
\end{tabular}

Table 4. Role of IABP in OPCAB-audit.

\begin{tabular}{ccccc}
\hline & $\begin{array}{c}\text { July 2002-Dec 2006 } \\
-1045 \text { Patients }\end{array}$ & $\begin{array}{c}\text { Jan 2007-Dec 2015 } \\
-3018 \text { Patients }\end{array}$ & P-value & \\
\hline CONVERSION & $1.8 \%$ & $0.03 \%$ & $<0.001$ & Significant \\
INOTROPIC USE & $75 \%$ & $2 \%$ & $<0.001$ & Significant \\
RENAL FAILURE & $3 \%$ & $0.3 \%$ & 0.001 & Significant \\
PERI OP MI & $1 \%$ & $0.2 \%$ & 0.002 & Not Significant \\
STROKE & $0.4 \%$ & $0.2 \%$ & 0.292 & Not Significant \\
MORTALITY & $0.76 \%$ & $0.36 \%$ & 0.115 & Significant \\
\hline
\end{tabular}

We have had two patients who had to be taken back for ventricular arrhythmia, in early days, post operatively and had to have IABP inserted and re-opened (Table 5). They were not the ones who had IABP inserted before. They had graft occlusion post operatively and had developed post-operative MI (Myocardial infarction).

We followed up all the patients who had IAB inserted during OPCAB, for survival after surgery. Table 6 shows the cause of death in these patients, the time duration after surgery and the place of death in all these patients.

The other advantage we noticed in this technique is that; in a single surgeon center like ours, where we are able to remove the IAB in the OT itself, then we could still go on with the second surgery, when only one IABP was available as a standby. 
Table 5. Last conversion from OFF PUMP to ON PUMP details.

\begin{tabular}{cccccc}
\hline Date & PT name & Age & Diagnosis & Surgery & Remarks \\
\hline 26-07-04 & Mr. MK & 67/M & CAD/TVD/HTN/DM EF 30\% & CABGX 4 & Quick primimg/CPB/spontaneous pick up \\
30-07-07 & Mr. AK & 55/M & CAD/TVD EF 60\% & CABGX 4 & $\begin{array}{c}\text { Intractable vt/vf patient crashed/IABP } \\
\text { supported quick priming-CPB/spontaneous } \\
\text { pick up/IABP removed in OT }\end{array}$ \\
\hline
\end{tabular}

Table 6. Role of IABP-patients who died after having IABP used during OPCAB surgery.

\begin{tabular}{|c|c|c|c|c|c|c|c|c|c|}
\hline SLNO & MIMS NO & SEX & AGE & DOS & DOD & Cause & Survival & Remarks & Surgery \\
\hline 1 & 188159 & M & 47 & 06.05 .05 & $20 / 06 / 11$ & Heart Attack & $6.5 \mathrm{yrs}$ & Outside & OРСАВХ01 \\
\hline 2 & 198240 & M & 59 & 09.07.05 & $24 / 05 / 10$ & $\begin{array}{l}\text { Cardiac } \\
\text { Arrest }\end{array}$ & 5 yrs & $\begin{array}{l}\text { Post Op } \\
\text { In Hospital } \\
\text { Death }\end{array}$ & ОРСАВХ03 \\
\hline 3 & 12835 & M & 77 & 07.03.06 & $11 / 03 / 06$ & $\begin{array}{c}\text { Met } \\
\text { Encephalopathy }\end{array}$ & 4 days & In Hospital & $\begin{array}{c}\text { REDO } \\
\text { OPCABX02 }\end{array}$ \\
\hline 4 & 172533 & $\mathrm{~F}$ & 60 & 24.07 .08 & $22 / 09 / 10$ & Heart Attack & 2 yrs & Outside & ОРСАВХ02 \\
\hline 5 & 529251 & M & 46 & 28.06 .10 & 05/02/11 & Heart Attack & 7 mths & Outside & ОРСАВХ03 \\
\hline 6 & 621391 & M & 51 & 23.06.11 & 07/07/11 & Cardiac Arrest & 14 days & In Hospital & OPCABX01 \\
\hline 7 & 733639 & M & 63 & 08/09/12 & 28/09/13 & $\begin{array}{l}\text { Pulmonary } \\
\text { Oedema }\end{array}$ & 1 yr 20 days & $\begin{array}{l}\text { Post Op } \\
\text { In Hospital } \\
\text { Death }\end{array}$ & ОРСАВХ03 \\
\hline
\end{tabular}

\section{Discussion}

The surgical results of coronary artery bypass grafting (CABG) without cardiopulmonary bypass or OPCAB have demonstrated several advantages by avoiding the potentially detrimental effects of cardiopulmonary bypass and eliminating intraoperative global myocardial ischemia [8]-[11]. In spite of many studies and results, less than fifteen percent of centers in the world are now performing OPCAB routinely. In India, over the last fifteen years, only centers who could deliver good results in terms of patency have continued this technique.

In our pursuit to perform all the coronary bypass surgeries without the use of $\mathrm{CPB}$, we started using IABP early in our experience. This has helped us not only in avoiding CPB, but also in avoiding inotropes in most of our patients.

IABP has been shown to provide a reduction in the ventricular after load, improvement in diastolic coronary perfusion, and enhancement of subendocardial perfusion [12]-[14]. In early days, the indications for preoperative IABP implantation were very restrictive because of the potential detrimental effects associated with the use of the device. The optimal timing for insertion of the IABP pre-operatively was well demonstrated by Christenson et al. in the era of on pump CABG. In those days, a 24-hour preoperative period of IABP treatment was found to result in a better postoperative cardiac index than shorter treatment of 1 to 2 hours of preoperative IABP support, with no impact on hospital mortality or postoperative morbidity. But in the present scenario of sicker, older, and patients with co-morbidities, it is important to use the IABP only when absolutely necessary. Postoperative IABP insertion has been disappointing owing to an associated high mortality rate and a high device-related complication rate. Avoiding high inotropic support in these patients could prevent visceral and peripheral malperfusion, which occurs due to peripheral and visceral vasoconstriction. Hemodynamic compromise occurs more often in high-risk patients [15].

We have not used preoperative IABP therapy, except when patient had to be wheeled into OT with an IABP in situ. We noticed that the actual high risk patients were the patients with good left ventricular function but, with ongoing ischemia and not the patients with low EF or even with critical left main stenosis. Christenson et al. [16] presented a prospective randomized study to evaluate the efficacy and safety of preoperative and perioperative IABP in high-risk OPCAB surgery. They concluded that pre- and perioperative IABP offered efficient he- 
modynamic support during high-risk OPCAB and was safe and shortened both intensive care unit and hospital length of stay [16]. Our experience with intraoperative IABP use and its removal after use has been different from theirs.

We did not inflate the IAB in any high risk patients unless they developed hemodynamic compromise. And we did not use inotrope as the first line of support. IABP was the first line of support, when hemodynamic compromise was noticed while the heart was lifted.

Vascular complications associated with use of IABP are not uncommon. Other major complications associated with the use of IABP include aortic dissection, paraplegia, bacteremia, mesenteric infarction, balloon rupture, and balloon entrapment [17] [18].

In our series of OPCAB procedures over the last thirteen years, we were able to prospectively monitor and study each of our patients in detail, so as to avoid the earlier mentioned complications. As a dedicated center for OPCAB surgery we were keen on performing all our CABGs off-pump, and in our drive to attain that goal, we have re-engineered the technique of OPCAB [19]. We have always used sheathless insertion of IABP, and have monitored the lower limb intra- and post-operatively to avoid the vascular complication of the device as well.

Recently, Mannacio et al. [20] have shown that two hours of preoperative IABP treatment improved cardiac performance, reduced inotropic requirements, and shortened ICU and hospital length of stay significantly. Preoperative insertion of IABP was safe and not associated with postoperative significant complications regardless of the counter pulsation time. Our technique of shortening the time of use of IABP has helped the patients in this regard.

We have modified the role of IABP in OPCAB to include: using a femoral arterial line in all patients undergoing OPCAB in our center; using IABP when absolutely necessary intra-operatively; being able to remove them after the surgery is over, in all our patients; and finally by redefining the group of high risk patients. Hence, our present approach is to perform surgery with an open mind; given that, any patient could be a potential candidate for an IABP. When hemodynamic compromise occurs during the positioning of the heart, then, instead of starting inotropes, IABP should be used to stabilize the heart during the distal anastomosis. With these modifications, we were able to perform OPCAB safely in all patients who needed CABG, thereby reducing our mortality and postoperative complication rate.

The limitation in this study was that it was more of an audit of our off-pump work which we had been doing for the past thirteen years.

\section{Conflict of Interest}

None declared.

\section{References}

[1] Suzuki, T., Okabe, M., Handa, M., Yasuda, F. and Miyake, Y. (2004) Usefulness of Preoperative Intraaortic Balloon Pump Therapy during Off-Pump Coronary Artery Bypass Grafting in High-Risk Patients. Annals of Thoracic Surgery, 77, 2056-2059. http://dx.doi.org/10.1016/j.athoracsur.2003.12.027

[2] Kim, K.B., Lim, C., Ahn, H. and Yang, J.K. (2001) Intra-Aortic Balloon Pump Therapy Facilitates Posterior Vessel Off-Pump Coronary Artery Bypass Grafting in High-Risk Patients. Annals of Thoracic Surgery, 71, 1964-1968. http://dx.doi.org/10.1016/S0003-4975(01)02638-8

[3] Calafiore, A.M., Teodori, G., Di Giammarco, G., et al. (1999) Multiple Arterial Conduits without Cardiopulmonary Bypass: Early Angiographic Results. Annals of Thoracic Surgery, 67, 450-456. http://dx.doi.org/10.1016/S0003-4975(98)01194-1

[4] Baumgartner, F.J., Gheissari, A., Capouya, E.R., Panagiotides, G.P., Katouzian, A. and Yokoyama, T. (1999) Technical Aspects of Total Revascularization in Off-Pump Coronary Bypass via Sternotomy Approach. Annals of Thoracic Surgery, 67, 1653-1658. http://dx.doi.org/10.1016/S0003-4975(99)00286-6

[5] Spooner, T.H., Hart, J.C. and Pym, J. (1999) A Two-Year, Three Institution Experience with the Medtronic Octopus: Systematic Off-Pump Surgery. Annals of Thoracic Surgery, 68, 1478-1481. http://dx.doi.org/10.1016/S0003-4975(99)00966-2

[6] Weinschelbaum, E.E., Machain, A., Raffaelli, H.A., et al. (2000) Off-Pump Coronary Operation at the Favaloro Foundation: Results in 264 Patients. Annals of Thoracic Surgery, 70, 1030-1033. http://dx.doi.org/10.1016/S0003-4975(00)01779-3

[7] Gutfinger, D.E., Ott, R.A., Miller, M., et al. (1999) Aggressive Preoperative Use of Intraaortic Balloon Pump in Elder- 
ly Patients Undergoing Coronary Artery Bypass Grafting. Annals of Thoracic Surgery, 67, 610-613. http://dx.doi.org/10.1016/S0003-4975(98)01201-6

[8] Bouchard, D. and Cartier, R. (1998) Off-Pump Revascualrization of Multivessel Coronary Artery Disease Has a Decreased Myocardial Infarction Rate. European Journal Cardio-Thoracic Surgery, 14, 20-24. http://dx.doi.org/10.1016/S1010-7940(98)00099-2

[9] Penttilä, H.J., Lepojärvi, M.V.K., Kaukoranta, P.K., Kiviluoma, K.T., Ylitalo, K.V. and Peuhkurinen, K.J. (1999) Myocardial Metabolism and Hemodynamics during Coronary Surgery without Cardiopulmonary Bypass. Annals of Thoracic Surgery, 67, 683-688. http://dx.doi.org/10.1016/S0003-4975(98)01344-7

[10] Matata, B.M., Sosnowski, A.W. and Galiñanes, M. (2000) Off-Pump Bypass Graft Operation Significantly Reduces Oxidative Stress and Inflammation. Annals of Thoracic Surgery, 69, 785-791. http://dx.doi.org/10.1016/S0003-4975(99)01420-4

[11] Ascione, R., Lloyd, C.T., Underwood, M.J., Lotto, A.A., Pitsis, A.A. and Angelini, G.D. (2000) Inflammatory Response after Coronary Revascularization with or without Cardiopulmonary Bypass. Annals of Thoracic Surgery, 69, 1198-1204. http://dx.doi.org/10.1016/S0003-4975(00)01152-8

[12] Gill, C., Wechsler, A., Newman, G., et al. (1975) Augmentation and Redistribution of Myocardial Blood Flow during Acute Ischemia by Intraaortic Pumping. Annals of Thoracic Surgery, 16, 44-53.

[13] Watson, J.T., Willerson, J.T., Fixler, D.E., et al. (1974) Temporal Change in Collateral Coronary Blood Flow in Ischemic Myocardium during Intra-Aortic Balloon Pumping. Circulation, 50, 249-254.

[14] Maccioli, G.A., Lucas, W.J. and Norfllet, E.A. (1988) The Intra-Aortic Balloon Pump: A Review. Journal of Cardiothoracic and Vascular Anesthesia, 2, 365-373. http://dx.doi.org/10.1016/0888-6296(88)90320-1

[15] Beauford, R.B., Goldstein, D.J., Sardari, F.F., et al. (2003) Multivessel Off-Pump Revascularization in Octogenarians: Early and Midterm Outcomes. Annals of Thoracic Surgery, 76, 12-17. http://dx.doi.org/10.1016/S0003-4975(03)00014-6

[16] Christenson, J.T., Licker, M. and Kalangos, A. (2003) The Role of Intra-Aortic Counterpulsation in High-Risk OPCAB Surgery: A Prospective Randomized Study. Journal of Cardiac Surgery, 18, 286-294. http://dx.doi.org/10.1046/j.1540-8191.2003.02030.x

[17] Dietl, C.A., Berkheimer, M.D., Woods, E.L., et al. (1996) Efficacy and Cost-Effectiveness of Preoperative IABP in Patients with Ejection Fraction of 0.25 or Less. Annals of Thoracic Surgery, 62, 401-409. http://dx.doi.org/10.1016/0003-4975(96)00244-5

[18] Christenson, J.T., Badel, P., Simonet, F., et al. (1997) Preoperative Intraaortic Balloon Pump Enhances Cardiac Performance and Improves the Outcome of Redo CABG. Annals of Thoracic Surgery, 64, 1237-1244. http://dx.doi.org/10.1016/S0003-4975(97)00898-9

[19] Vettath, M., Ismail, E. and Kannan, A. (2013) Re-Engineering in OPCAB-A Vettath’s Perspective. World Journal of Cardio Vascular Disease, 3, 33-44. http://dx.doi.org/10.4236/wjcd.2013.34A006

[20] Phillips, S.J., Tannenbaum, M., Zeff, R.H., et al. (1992) Sheathless Insertion of the Percutaneous Intraaortic Balloon Pump: An Alternate Method. Annals of Thoracic Surgery, 53, 162-164. http://dx.doi.org/10.1016/0003-4975(92)90782-Y

\section{Submit or recommend next manuscript to SCIRP and we will provide best service for you:}

Accepting pre-submission inquiries through Email, Facebook, Linkedin, Twitter, etc

A wide selection of journals (inclusive of 9 subjects, more than 200 journals)

Providing a 24-hour high-quality service

User-friendly online submission system

Fair and swift peer-review system

Efficient typesetting and proofreading procedure

Display of the result of downloads and visits, as well as the number of cited articles

Maximum dissemination of your research work

Submit your manuscript at: http://papersubmission.scirp.org/ 